\title{
ILANA: APOSTANDO EM UMA ASSOCIAÇÃO DE HISTORIADORES
}

\author{
Holien Gonçalves Bezerra \\ Prof. Aposentado da PUC/SP e da UFGO
}

\begin{abstract}
A
presença vigorosa de Ilana acompanhou-me por quase três décadas. Lembrome ainda de sua presença, nas primeiras fileiras, em aulas do "prédio velho" da PUC, quando foi minha aluna em seu último ano de graduação, em 1970. Em 1974, já figura como Auxiliar de Ensino, na equipe de professores que trabalhava a disciplina Pesquisa Histórica, ainda iniciando seus passos relutantes mas entusiastas, como docente de um Departamento carregado das utopias dos anos 70. Imbuída dos ideais de uma nova universidade, Ilana compartilhava conosco de três grandes propósitos: a formação de profissionais que atuassem criticamente em seus ambientes de trabalho; a produção do conhecimento; a transformação da sociedade. Foram anos de trabalho em equipe, em que sobressaiam a garra e a vontade, que beiravam até o voluntarismo, típico de idealistas acima de quaisquer outros interesses. O clima era de corresponsabilidade, dedicação e otimismo. Apesar dos percalços do momento político da ditadura militar e das dificuldades econômico-financeiras da universidade, sentia-se no ar uma gratificação pelo trabalho, que poderia parecer um misto de dedicação e de missão.

Trazer à memória este clima, no qual conviveu Ilana, é apenas um relembrar que nos ajuda a entender muito de sua personalidade. A convivência em um ambiente de trabalho construtivo, que perdurou por aproximadamente dez anos, não foi deixado de lado quando passou a trabalhar no Departamento de História da USP. Estes dois períodos - o puquiano e o uspiano - já estão sendo relembrados por outros colegas. Cabe-me a honra de enfocar a passagem de Ilana pela nossa ANPUH. Mais
\end{abstract}


uma vez tive a oportunidade de partilhar com ela preocupações, utopias e muito trabalho. Algumas poderiam ser pontuadas. Minhas lembranças situam-se nos períodos em que integramos a Diretoria Nacional: gestões 91-93 e 93-95, em que Ilana ocupou, por duas vezes seguidas, a tesouraria da Associação. Tanto na primeira como na segunda gestões, a equipe constituída fazia questão da presença de Ilana como integrante de chapa. Posteriormente, entre 97 e 99, teve assento no Conselho Editorial da Revista Brasileira de História e no Conselho Consultivo da Anpuh-nacional. No total, portanto, foram seis anos de dedicação à nossa Associação. E não era apenas "pra constar", pois Ilana não se prestava a esse tipo de engajamento pela metade. A dedicação, à Anpuh, como em todos os seus empreendimentos, foi sempre "pra valer"

Não foram poucas as vezes que conversamos sobre o sentido de dedicarmos tempo e trabalho a uma associação de profissionais que vivia quase da teimosia de alguns abnegados. Pensar a Anpuh era trazer à mente as figuras que nela apostaram, como o Prof. Eurípides Simões de Paula, Raquel Glezer, e alguns outros que igualmente permaneceram por mais tempo à frente da Associação. Valeria a pena nos dedicarmos a uma instituição que tinha tantas dificuldades para se manter e se mostrar à comunidade dos historiadores, tradicionalmente tão individualista? As dúvidas eram muitas, eram mútuas, e também de muitos professores que se dispunham, por insistência de colegas, a assumir algum cargo na Anpuh. Daí as reflexões que surgiam das conversas que tínhamos com freqüência. Talvez o que mais nos impulsionou a trabalharmos juntos foi aquele aprendizado que vivenciamos nos difíceis tempos dos anos 70 e 80, certamente responsáveis por forjar personalidades como a de Ilana.

Molas as mais diversas podem levar as pessoas a se disporem a assumir compromissos com associações do tipo da Anpuh e assemelhadas. Pode ser o desejo de apresentar-se ao público, massageando seu ego, no ímpeto de aparecer. Podem aparecer carreiristas, que vêm nesta função uma possibilidade de trampolim para imaginadas melhores colocações na carreira acadêmica. Ou, como em geral acontece, são professores que sentem a necessidade de colaborar com o conjunto dos profissionais da área de História, no sentido de construir um espaço organizacional que articule as potencialidades intelectuais e de produção do conhecimento presentes 
nos profissionais da História e nas instituições voltadas para o ensino e a pesquisa na área. A convicção da necessidade de fortalecimento do campo de interlocução tanto da produção historiográfica quanto do ensino de História foi a mola que impulsionou as vontades das equipes que ocuparam a Diretoria Nacional, nos quatro anos em que tivemos o concurso de Ilana compondo o grupo de trabalho. Se conseguimos alguma coisa de positivo, foi graças a este espírito de equipe que congraçou pessoas amigas, que não podem deixar de ser mencionadas: Maria Helena Capelato, Luis Carlos Soares e Ilana. Com a presença amiga, franca, disponível destes professores foi-nos possível construir algumas ações que ocupam um lugar de destaque na vida da Anpuh. Em homenagem à Ilana, vale a pena relembrá-las, ficando como uma marca de sua passagem entre nós.

Na gestão 91-93, assumimos, Ilana, Luís Carlos e eu próprio, a gestão da Associação, em todos os seus aspectos, em vista da Secretária Geral ter se ausentado do país para o pós-doutorado e o Presidente residir no Rio de Janeiro. Foram momentos difíceis, não contávamos com secretaria nacional organizada, faltos de recursos mínimos como telefone, computador, secretária permanente. A infra-estrutura com a qual contamos atualmente, foi fruto dos esforços da gestão 93-95, com a implantação do Projeto de Pós-graduação, seguidamente aprimorados pelas gestões seguintes, com o empenho valioso das Chefias do Departamento de História da USP. Mesmo com aquelas condições precárias, conseguimos manter a Anpuh em funcionamento, sendo grande o mérito de Ilana na preparação e realização do XVII Simpósio Nacional, sediado na USP, em 1993. Foi no decorrer deste evento que foram discutidos e aprovados os novos Estatutos da Anpuh, que passou a denominar-se Associação Nacional de História, universalizando-se sua abrangência a todos os profissionais da área, embora mantendo o nome fantasia, que faz referência aos professores universitários. Neste Simpósio foi eleita a nova diretoria nacional, mantendo-se Ilana na tesouraria. Iniciava-se um período profícuo e repleto de realizações duradouras, sempre com a presença marcante de nossa tesoureira.

O "Boletim da Anpuh" teve seu primeiro número publicado no segundo semestre de 93, com a finalidade de interligar de alguma forma os associados historiadores. 
Hoje já em sua $17^{\mathrm{a}}$ edição, o Boletim pode ser considerado um dinamizador da vida dos historiadores no Brasil, apesar de alguns percalços sofridos em sua trajetória. A criação do "Forum de Pós-graduação", que teve sua primeira reunião oficial durante o Simpósio na USP, em julho de 93, foi uma resposta objetiva e pertinente à busca de uma Pós-graduação em História para encontrar mecanismos que a aglutinasse e a fortalecesse, tendo em vista suas especifidades. A fundação de uma Associação Nacional de Pós-graduação em História, a exemplo do que acontece nas outras áreas de conhecimento, foi rejeitada unanimemente, pois poderia representar uma cisão na Associação. A ANPUH lutou e conseguiu manter a unidade de sua Associação, dedicando um forum especial para tratar dos assuntos da Pós-graduação em História. Com a segunda reunião realizada em Brasilia, no mês de novembro, o Forum se consolida. E foi a partir dele, também, que, providencialmente, a Anpuh Nacional encontrou o caminho seguro para entrar em uma nova perspectiva de atuação, mais condizente com sua abrangência nacional.

A elaboração do "Projeto Pós-Graduação - ANPUH: Pesquisa, Informação e Intercâmbio", enviado ao CNPq e aprovado, deu oportunidade para o desenvolvimento de muitas atividades extremamente valiosas para a área de História. O trabalho da coordenação coube à Secretária Geral da Anpuh-Nacional, na pessoa abnegada de Maria Helena Capelato, auxiliada de perto por Ilana. Recursos vieram em forma de auxílio à pesquisa, publicações, e de recursos para a aquisição de material de consumo e equipamentos, além de bolsas de IC e AP aos alunos de História, que passaram a colaborar de maneira eficiente na realização complexa dos trabalhos propostos. Na época, as dependências da sede da Anpuh, no prédio de Geografia e História da USP, fervilhavam de jovens estudantes trabalhando nos sub-projetos. Foi assim que se iniciaram variadas atividades: "Balanço da produção científica dos Programas de Pós-graduação", que resultou na elaboração de vários artigos de autoria de professores de algumas universida des como USP, PUC-SP, UNICAMP. Nesses artigos, houve um esforço para se perceber as tendências historiográficas dos centros de pesquisa em estudo, assim como os caminhos para os quais apontavam. 
Com a intenção de elaborar o levantamento de dados para informação dos programas de pós-graduação e da área de História em geral, vários instrumentais de trabalho foram elaborados. A relação das "Pesquisas em Andamento" dos 20 Programas então existentes possibilitou a informação e acompanhamento das temáticas em estudo, assim como a possibilidade de se conhecerem os professores orientadores e seus respectivos orientandos e os assuntos das teses e dissertações em andamento no Brasil. Os Programas de Pós-graduação tinham acesso a essa publicação, de certo modo de circulação restrita. Por outro lado, para que se tivesse uma visão mais realista da situação do pós-graduação no Brasil, procurou-se obter o "Perfil dos Programa de Pós-graduação", com todas as informações necessárias e úteis para os intercâmbios que se desejassem. Muito útil para esse diagnóstico foi a informação sobre as Áreas de Concentração dos Programas e suas Linhas de Pesquisa.

Ainda na perspectiva de oferecer aos profissionais da História um mapeamento da produção publicada e das pesquisas em andamento, a Anpuh conseguiu junto ao CNPq a verba necessária para a pesquisa e publicação dos principais indicadores que situam os historiadores brasileiros. Assim, depois de muito trabalho junto aos colegas do Brasil inteiro, conseguimos publicar o "Quem é Quem na História - Pesquisadores e Pesquisas no Brasil", que saiu publicado em 1996.

Outra produção importante, que auxiliou de forma substantiva o mapeamento das pesquisas em andamento foi a publicação da "Produção Histórica no Brasil 1985-1994 - Catálogo de Dissertações e Teses dos Programas e Cursos de Pósgraduação em História", que saiu em 3 volumes, em 1995.

Este conjunto de atividades não teria sido possível sem a participação paciente e permanente da Ilana. Sua capacidade de organização, aliada à simpatia que torna prazerosa as tarefas mais difíceis, garantiu à equipe que dirigia a Anpuh neste anos de trabalho, a satisfação de ver sua missão cumprida, sem os desgastes que são quase inerentes a quem se dedica à participação em uma associação das dimensões da Anpuh. A alegria de constatar o dever cumprido foi ainda maior quando da realização do XVIII Simpósio Nacional, com sede na Universidade Federal de Pernambuco, em julho de 1995: a quantidade e qualidade dos trabalhos apresentados e o número 
expressivo de participantes foi gratificante, para todos os que se empenharam nos estafantes afazeres da montagem do evento.

No entanto, não se limitou a isso a participação de Ilana em nossa Associação. Na gestão de 1997-99, participou do Conselho Consultivo da Anpuh Nacional assim como do Conselho Editorial da Revista Brasileira de História, como já foi lembrado anteriormente. Nestes dois Conselhos e, especialmente no Consultivo da RBH, do qual também fui membro, a presença da Ilana foi de um inestimável valor construtivo. Sua ponderação acompanhou os trabalhos da Revista, emprestando, em momentos difíceis, sua competência e senso de equilíbrio para a solução dos impasses.

Neste momento em que prestamos homenagem à Ilana, queremos expressarlhe, em nome dos colegas que com ela partilhamos momentos de trabalho, alegria e apreensões, nosso agradecimento por termos tido a sorte de conviver por todos estes anos com alguém que não poderia ter nos deixado tão cedo. De minha parte, com ela aprendi muito, e tive alento para prosseguir em trabalhos que exigiam de nossa parte idealismo e perseverança. Obrigado, Ilana, por você ter existido e por ter deixado, em todos nós da Anpuh, uma marca muito sua: companheirismo, competência, ética profissional e, sobretudo, amizade sincera. 